\title{
EDITORIAL
}

\section{Crisis y Coronavirus: El papel que juega la Ciencia}

La pandemia de Covid-19 comienza en Wuhan y se considera que los primeros pacientes se remontan a Diciembre de 2019 [1]. Desde entonces, el mundo ha experimentado, continente por continente, la conmoción que sigue al virus, develando lo que pareciera ser un enigma entre las prioridades de los países en cuanto a la salud y la economía. La novedad de la enfermedad vino acompañada de un amplio espectro de enfoques hacia la crisis global generada por el virus. Por un lado, algunas políticas se centraron en la idea de que la exposición al virus traería naturalmente la inmunización a la comunidad, como en el primer acercamiento del Reino Unido. Poco después, la conciencia sobre el colapso de los sistemas de salud impulsaría las medidas hacia un enfoque más intermedio.

Por otro lado, la idea del confinamiento total resultaba atractiva. Este enfoque también plantea un par de problemas. El primero está relacionado con el costo económico inmediato o de muy corto plazo de dicha medida, así como con las consecuencias a mediano y largo plazo sobre el crecimiento económico y sus implicaciones. El segundo tema está relacionado con la inmunización o, en este caso, la falta de ella. Las estrategias o enfoques puros parecen ser no factibles (colapso del sistema de salud) o bien no son asequibles (cierre económico por un período considerable). Por lo tanto, un enfoque de término medio parece ser un enfoque razonable para las economías de ingresos bajos, medianos o endeudados. Teniendo en cuenta que el ciclo del virus lleva años, se alcanzaría un estado de población completamente inmunizada mediante una estrategia que sigue un camino que evita el colapso del sistema de salud y promueve una recuperación económica que pueda afrontar tal política. Por lo tanto, el esfuerzo necesario en estos tiempos debe priorizar el bienestar de las personas en dos dimensiones: Condiciones de salud y Condiciones económicas.

\section{Perspectiva económica}

La perspectiva económica para el mundo se ha reducido debido al efecto del virus [2-4]. El brote de coronavirus ha afectado al crecimiento económico, el empleo y la pobreza en todo el mundo. Según Fitch Ratings, se espera que el PBI mundial se contraiga en un 3,9\% en el 2020, una recesión de una magnitud sin precedentes desde la Segunda Guerra Mundial. La situación actual sería dos veces más grave que la recesión del 2009. De manera similar, The Time informa que las economías europeas están en camino de una recesión sin precedentes debido a las medidas de cuarentena [2]. Además, la Organización Internacional del Trabajo prevé la pérdida de 12 millones de puestos de trabajo a tiempo completo en Europa en 2020 debido al brote de coronavirus [3]. En Estados Unidos, las solicitudes de seguro por desempleo aumentaron drásticamente. Las nuevas solicitudes elevaron el número total de solicitudes por desempleo, desde mediados de marzo hasta principios de mayo, a 33,3 millones. Este fenómeno fue la señal que precedió a la tasa de desempleo del 14,7\% en abril de 2020. Además, los jóvenes son especialmente vulnerables al impacto económico negativo del coronavirus. Por ejemplo, considerando la última recesión, el desempleo juvenil se vio afectado más profundamente que el desempleo en general. La evidencia preliminar sugiere que los trabajos de los jóvenes se concentran en los sectores más afectados. Por lo tanto, es más probable que pierdan su trabajo [4]. Además de esto, la evidencia también sugiere que un período significativo de desempleo puede tener un impacto perjudicial en el empleo a largo plazo y las perspectivas de ingresos de los jóvenes [5]. Son tiempos entonces, en los que el mundo está sufriendo contracción económica y desempleo en donde los que los jóvenes se ven especialmente afectados. Más aún, el Banco Mundial estima que 49 millones de personas serán empujadas a la pobreza extrema debido al impacto del Covid-19 [6]. 


\section{Crecimiento económico y productividad: investigación, conocimiento y cambios tecnológicos}

El crecimiento económico es una de las herramientas más poderosas para reducir la pobreza, reducir el desempleo y mejorar la calidad de vida. La investigación entre países, como también casos a nivel país, proporciona pruebas abrumadoras de que un crecimiento rápido y sostenido es fundamental para avanzar más rápidamente hacia la mejora de la pobreza y la recuperación de puestos de trabajo [7]. Se ha demostrado en la literatura que las diferencias en productividad explican alrededor del $90 \%$ de la diferencia entre países ricos y países en desarrollo. También se ha demostrado que aumentar la productividad es la forma más eficaz de mejorar el crecimiento económico [8]. Si la productividad impacta al crecimiento y el crecimiento impacta a la pobreza, el empleo y la calidad de vida, entonces la pregunta que surge es: ¿Cómo aumentar la productividad? Paul Romer (Premio Nobel de Economía en 2018) respondió a esta pregunta con su contribución a la comprensión de los modelos de crecimiento endógeno. La idea central es que la inversión en capital humano, innovación y conocimiento son determinantes cruciales del crecimiento económico [8]. Por tanto, la sociedad basada en el conocimiento debe ser el pilar fundamental para cambiar los efectos globales de la actual pandemia.

El capital humano, la innovación y el conocimiento son determinantes de los cambios tecnológicos que determinan la productividad. Por lo tanto, el papel de las universidades y las instituciones de investigación es crucial no solo para superar la situación actual, sino también para asegurar una senda de crecimiento y recuperación a mediano y largo plazo. El mundo está sufriendo un golpe y se avizoran tiempos difíciles. Sin embargo, la teoría y la evidencia muestran que la recuperación será tan rápida como la mejorar en productividad. Cuanto más invirtamos en capital humano, conocimiento e innovación, más rápido será el crecimiento y más rápido la recuperación.

La situación actual genera un estado económico en el que menos personas están produciendo bienes y servicios debido al recorte de mano de obra generado por la crisis del coronavirus en el mercado laboral. Además, como mencionamos anteriormente, la población joven se ve particularmente afectada. Utilizando una variación del modelo propuesto en [8] se puede mostrar que un aumento en la fracción de ideas generadoras (investigación) aumentará la tasa de crecimiento del conocimiento. Usando las ideas de Romer, referente al crecimiento endógeno, podríamos imaginar un estado alternativo de la economía en el que, si bien menos personas producen bienes y servicios debido a la crisis, la fracción de personas generando conocimiento e ideas aumenta (especialmente los más jóvenes). Lo anterior aumenta el conocimiento y el desarrollo tecnológico y por lo tanto el crecimiento económico de mediano y largo plazo. Es inevitable que el nivel producción per cápita del presente decaiga, sin embargo, la tasa de crecimiento aumenta y los niveles de producción per cápita pre crisis se recuperan en los años futuros. Por lo tanto, la recuperación economía será tan rápida como lo sea el aumento en generación de conocimientos y desarrollo tecnológico. De esta forma, hoy enfrentamos dos caminos distintos hacia el futuro. El primero representa la evolución económica actual sin cambios de paradigma. En este caso, hay consecuencias negativas inmediatas sobre el PBI, el empleo y la pobreza. Pero más preocupante aún, no habrá razones fundamentales para predecir o esperar una mejora en la senda de crecimiento futuro. El segundo se relaciona con la evolución económica cuando se toman medidas en el presente para incrementar el capital humano y el conocimiento. El modelo de Romer predice que las consecuencias negativas inmediatas sobre el PBI, el empleo y la pobreza son inevitables. Sin embargo, existen razones fundamentales para predecir y esperar una recuperación más rápida y mejores niveles de calidad de vida futuros.

Invertir en capital humano y ciencia hoy facilitará el trabajo con futuras crisis. Aunque no podemos prever de qué se tratará la próxima crisis, podemos asegurarnos de que estaremos mejor preparados. Un ejemplo para ilustrar mejor este punto es el siguiente. En 1968, en los respiraderos térmicos de Yellowstone, Thomas Brock, un microbiólogo de la Universidad de Wisconsin, descubrió una forma 
de bacteria (Thermus aquaticus) que puede sobrevivir a temperaturas muy altas [9]. En 1976, la Dra. Alice Chien y otros descubrieron e informaron de la purificación y caracterización de ADN polimerasa de la Thermus aquaticus [10]. Luego, en 1985, el Dr. Kary Mullis inventó el proceso conocido como reacción en cadena de la polimerasa (PCR) por el que obtuvo el Premio Nobel de Química en 1993. Es decir, décadas más tarde, el descubrimiento de la Thermus Aquaticus ha demostrado ser vital en lo que hoy es la base fundamental de la estrategia mundial destinada a contener el brote. El PCR es nuestra primera línea de defensa en esta situación actual. Es importante notar que esta herramienta esencial está disponible en el presente debido al trabajo científico que comenzó hace unos cincuenta años.

Finalmente, es esencial tener en cuenta que, durante el brote actual de Coronavirus, muchos puestos de trabajo se suspenden, retrasan o definitivamente se pierden. Esto se debe a que las tareas asociadas a esos trabajos probablemente no se realicen o no sean financieramente viables. Sin embargo, los puestos académicos y de investigación son, en la mayoría de los casos, no solo viables sino necesarios. Las universidades y las instituciones de investigación pueden allanar el camino para restaurar la economía. Además, las Universidades e Instituciones de Investigación pueden acercarnos al tratamiento adecuado del virus. En resumen, los trabajos académicos y de investigación, es decir, la ciencia, pueden ser la clave para la recuperación y la clave para abrazar en mejores condiciones crisis futuras.

\section{REFERENCIAS}

[1] P. Zhou, et al. "A pneumonia outbreak associated with a new coronavirus of probable bat origin". Nature. Vol. 579, pp. 270273. 2020. URL: https://doi.org/10.1038/ s41586-020-2012-7

[2] Associated Press. "European Economies on Course for Unprecedented Recession due to Coronavirus Lockdown Measures". 2020. URL: https://time.com/5826084/ european-economies-recession-coronavirus/

[3] ILO. "ILO: Covid-19 causes devastating losses inworking hours and employment". (2020). URL: https://www.ilo.org/global/aboutthe-ilo/newsroom/news/WCMS_740893/ lang--en/index.htm

[4] S. Evans and J. Dromey. "Coronavirus and the labour market: impacts and challenges". 2020. URL: https://www.learningandwork. org.uk/resource/coronavirus-and-the-labourmarket-impacts-and-challenges/

[5] P. Gregg and E. Tominey. "The wage scar from youth unemployment". Leverhulme Centre for Market and Public Organization. University of Bristol, UK. 2004.
[6] D. Gerszon, et al. "The impact of COVID-19 (Coronavirus) on global poverty: Why SubSaharan Africa might be the region hardest hit". The World Bank Group. 2020. URL: https://blogs.worldbank.org/opendata/impactcovid-19-coronavirus-global-poverty-whysub-saharan-africa-might-be-region-hardest

[7] P. Aghion and P. Howitt. "Growth and unemployment". The Review of Economic Studies. Vol. 61, pp. 477-494. 1994. URL: https://doi.org/10.2307/2297900

[8] P.M. Romer. "Endogenous technological change". Journal of political Economy. Vol. 98, pp. S71 S102. 1990. URL: https:// www.jstor.org/stable/2937632

[9] T.D. Brock. "The value of basic research: discovery of Thermus aquaticus and other extreme thermophiles". Genetics. Vol. 146, pp. 1207-1210. 1997. URL: https://www. genetics.org/content/146/4/1207

[10] A. Chien, D.B. Edgar and J.M. Trela. "DNA polymerase from the extreme thermophile Thermus aquaticus". J. Bact. Vol. 127, pp. 1550. 1976.

\author{
Dr. Gonzalo Valdés \\ Universidad de Tarapacá \\ Departamento de Ingeniería Industrial y de Sistemas \\ Arica, Chile \\ E-mail: gvaldes@uta.cl
}

\author{
Dr. David Laroze \\ Universidad de Tarapacá \\ Instituto de Alta Investigación \\ Arica, Chile \\ E-mail: dlarozen@uta.cl
}

